\title{
Laparoscopy-Assisted Transduodenal Papillectomy
}

\author{
Goro Honda $^{a}$ Masanao Kurata ${ }^{a}$ Hideki Matsumura $^{a}$ Hiroshi Matsumoto $^{a}$ \\ Terumi Kamisawab Naoto Egawab \\ Departments of ${ }^{a}$ Hepato-Biliary-Pancreatic Surgery and ${ }^{b}$ Internal Medicine, Tokyo Metropolitan Komagome \\ Hospital, Tokyo, Japan
}

\section{Key Words}

Adenocarcinomas $\cdot$ Endoscopy $\cdot$ Laparoscopy ·

Pancreatoduodenectomy $\cdot$ Transduodenal Papillectomy

\begin{abstract}
Background/Aims: Basically, patients with cancer of the major duodenal papilla should undergo pylorus-preserving pancreatoduodenectomy; however, patients with adenoma or cancer in adenoma do not require prophylactic lymph node dissection, so they are indicated for limited resection of the major duodenal papilla. Endoscopic snare resection (ESR) has developed as limited resection of the major duodenal papilla; however, the ESR technique is still restricted to certain centers, because its outcome depends on the technical skills of the endoscopist. Therefore, we attempted laparoscopy-assisted transduodenal papillectomy (LATDP). Methods: Ports were placed at the umbilicus, upper abdomen, left hypochondrium and right flank. Initially, kocherization was performed, followed by laparoscopic cholecystectomy, and a C-tube was placed in the common bile duct through the cystic duct. Next, the port wound of the upper abdomen was extended $4 \mathrm{~cm}$ longitudinally, and only the descending part of the duodenum was extracted through this incision. The duodenum was opened opposite to the major duodenal papilla, and the major duodenal papilla was resected extracorporeally. After resection, the resection stumps of the bile duct and the pancreatic duct were sutured along with the duodenal mucosa. Lastly, the incision in the duodenum was stitched. Results: We performed LATDP in 2
\end{abstract}

patients with cancer in adenoma. These patients had uneventful postoperative courses, as had patients who had previously undergone transduodenal papillectomy (TDP) by the open method in our hospital. Conclusion: LATDP is a feasible procedure that can be substituted for TDP and is less invasive after ESR.

Copyright $\odot 2010$ S. Karger AG, Basel

\section{Introduction}

The management criteria for adenocarcinomas of the major duodenal papilla have already been established [1, 2]. Basically, pylorus-preserving pancreatoduodenectomy should be performed even for early carcinoma [3]; however, in cancers of the major duodenal papilla not extending beyond the sphincter of Oddi (UICC: Tis or $\mathrm{T}_{1}$ ), the rate of lymph node metastases is low [4]. Therefore, limited resection of the major duodenal papilla without prophylactic lymph node dissection can be considered in patients with carcinoma in situ (Tis) or $\mathrm{T}_{1}$ tumors [5]; however, at present, it is difficult to diagnose cancer invasion to the sphincter of Oddi using imaging modalities or endoscopic biopsy preoperatively [6]. Consequently, limited resection of the major duodenal papilla without prophylactic lymph node dissection is indicated only for adenoma, which is well known as a premalignant lesion because of the adenoma-carcinoma sequence [7], or cancer in adenoma (Tis) [4]. During the past decade, endoscopic snare resection (ESR) has been employed for limited resection

\section{KARGER}

Fax +4161306 1234 E-Mail karger@karger.ch www.karger.com

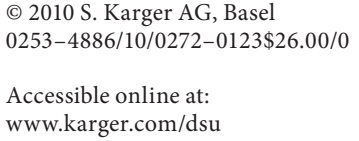

Goro Honda, MD

Department of Hepato-Biliary-Pancreatic Surgery

Tokyo Metropolitan Komagome Hospital

3-18-22 Honkomagome, Bunkyo-ku, Tokyo 113-8677 (Japan)

Tel. +81 33823 2101, Fax +81 33824 1552, E-Mail ghon@ax3.mopera.ne.jp 


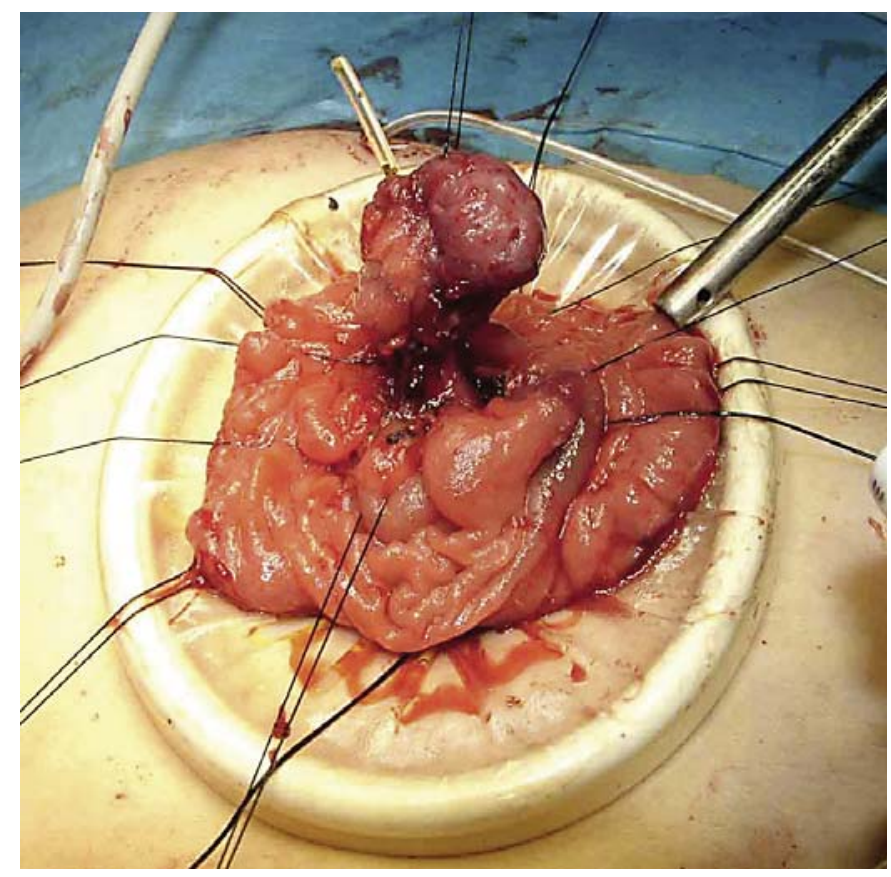

Fig. 1. Intraoperative findings of a 61-year-old woman. The duodenum has been opened opposite to the major duodenal papilla with a minimal wound $(4 \mathrm{~cm})$. Because this region could be fixed firmly due to exposure via the minimum incision, good vision was possible. The duodenum around the major duodenal papilla was spread by traction sutures. The mucosa around the tumor of the major duodenal papilla was dissected using a mucosal margin of $0.5-1 \mathrm{~cm}$, and the biliary and pancreatic ducts are seen in the center of this view. Subsequently, we cut both ducts and removed the specimen. The tip of the $\mathrm{C}$-tube protruding from the major duodenal papilla is seen.

of the major duodenal papilla $[8,9]$. A recent series of ESR (a technique requiring excellent skills, e.g. stent placement or balloon catheter traction preresection) reported a lower incidence of complications (e.g. bleeding or acute pancreatitis) and recurrence $[10,11]$. However, because the outcome of the patient treated with ESR depends on the technique of the endoscopist, not all patients can enjoy the benefit of ESR, and transduodenal papillectomy (TDP) is performed, which is more invasive than ESR [6]. We therefore attempted laparoscopy-assisted TDP (LATDP), a less invasive method, and assessed the incidence of complications and recurrence.

\section{Patients and Methods}

Patients were in the supine position under general anesthesia. Ports were placed at the umbilicus, upper abdomen, left hypochondrium and right flank. Initially, kocherization was per-

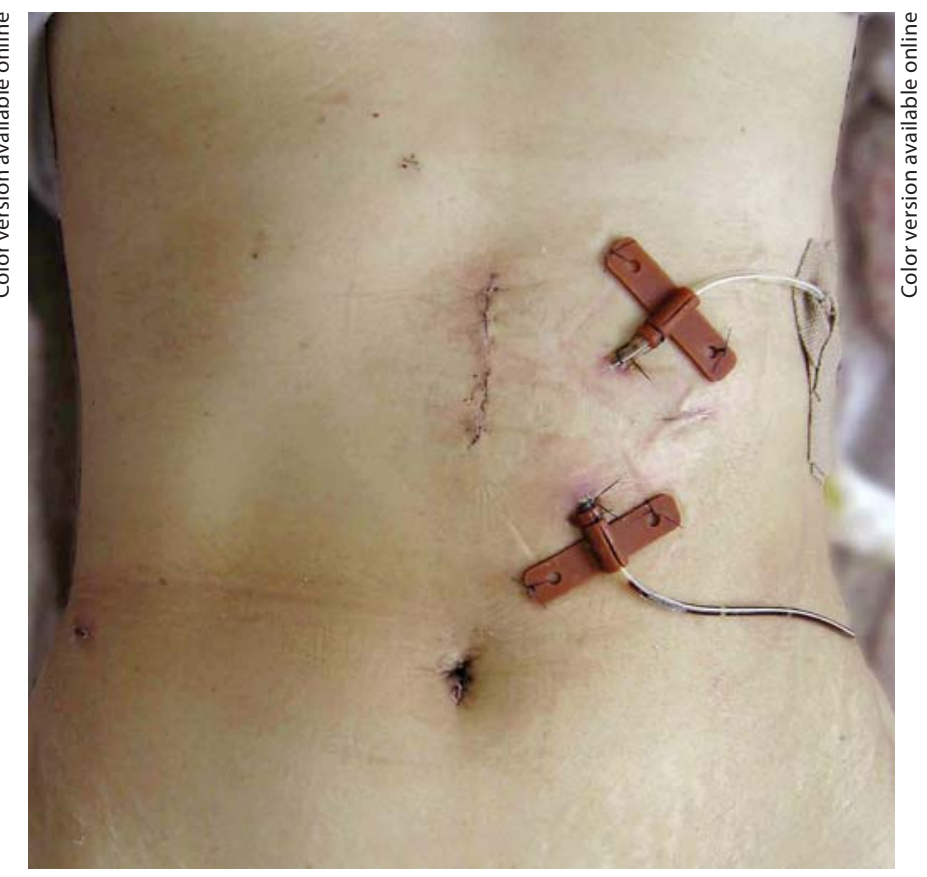

Fig. 2. Postoperative abdominal findings in a 61-year-old woman. There is $4-\mathrm{cm}$ wound at the upper midline. The gastrostomy tube and intestinal fistula tube are still in place. The C-tube, which was advanced from the epigastric region, has already been removed, as has the indwelling suction tube, the tip of which was placed behind the pancreas head via the port of the right flank.

formed. Additionally, to have the major duodenal papilla at the abdominal wall, we mobilized the hepatic flexure of the colon and dissected the mesenterium of the transverse colon from the duodenum, because the major duodenal papilla is usually located near the transverse portion of the descending part of the duodenum. Laparoscopic cholecystectomy was performed, and a cystic duct tube (C-tube) was placed in the duodenum through the cystic duct and the common bile duct. Next, the port wound of the upper abdomen was extended to $4 \mathrm{~cm}$ longitudinally, and only a small part of the duodenum, which included the major duodenal papilla, was extracted through this incision. The location of the major duodenal papilla was determined by palpating the tip of the $\mathrm{C}$-tube in the duodenum through the major duodenal papilla. The duodenum was opened opposite to the major duodenal papilla, and then the duodenum around the major duodenal papilla was spread using 6-8 traction sutures which had been stitched through the whole layer of the duodenum (fig. 1). In this way, the major papilla could be resected extracorporeally under good vision, and a sufficient tumor margin could be achieved. After resection, the tip of the C-tube was advanced into the common bile duct and a stent was placed in the pancreatic duct. Both ducts were sutured at segments abutting each other to make one orifice. They were then sutured along with the duodenal mucosa. Lastly, the incision in the duodenum was stitched, and the gastrostomy tube and the intestinal fistula tube were placed, respectively; the indwelling suction tube was placed behind the pancreas head through the port wound in the right flank (fig. 2). 


\section{Results}

We performed LATDP in 2 patients (a 61-year-old woman and a 54-year-old man) with cancer in adenoma of the major duodenal papilla. The former underwent simultaneous resection of ectopic hepatocellular carcinoma located at the triangle ligament under the left diaphragm. Surgery lasted $242 \mathrm{~min}$, and estimated blood loss was $70 \mathrm{ml}$. Food intake started on postoperative day (POD) 6 and she was discharged on POD 15. The other patient was a well-built obese man, so it was problematic to extract the part of the duodenum which included the major duodenal papilla. Once we had extended the port wound of the upper abdomen to $4 \mathrm{~cm}$ longitudinally, we insufflated again and dissected the pancreas head and the colon from the retroperitoneum additionally to facilitate excision of the major duodenal papilla. The duration of surgery was $174 \mathrm{~min}$, and the estimated blood loss was $134 \mathrm{ml}$. Food intake started on POD 5 and he was discharged on POD 11. These patients had uneventful postoperative courses, as had patients who had previously undergone surgery by the open method in our hospital.

\section{Discussion}

Some authors have reported TDP for adenocarcinoma extending beyond the sphincter of Oddi for high-risk patients not eligible for extensive surgical procedures or patients refusing surgery $[12,13]$, but tumor recurrence rate was high. Basically, patients with cancer of the major duodenal papilla should undergo pylorus-preserving pancreatoduodenectomy, and in patients with adenoma or cancer in adenoma, prophylactic lymph node dissection is not required [4]. Regarding tumor size, only tumors measuring 3-4 cm in diameter can be resected, since the upper size limit for the reconstruction of a mucosal defect is $\sim 5 \mathrm{~cm}$, including a mucosal margin around the tumor of $0.5-1 \mathrm{~cm}[14,15]$. These criteria for the resection of the major duodenal papilla apply to both TDP and LATDP.

Because the descending portion of the duodenum, where the major duodenal papilla is located, encircles the periphery of the pancreas head, it is shifted from the retroperitoneum to the most ventral side just on the median line by sufficient mobilization of the pancreas head. Therefore, the TDP wound can be minimized $(\sim 4 \mathrm{~cm})$ by laparoscopic mobilization of the pancreas head. The wound is made by extending the port wound of the upper abdomen. The major duodenal papilla is usually located near the transverse portion of the descending portion of the duodenum, so it is very important to mobilize the transverse portion of the duodenum for sufficient mobilization of the pancreas head. Therefore, mobilizing the hepatic flexure of the colon concurrently and dissecting the mesenterium of the transverse colon from the duodenum, preparing to rotate the patient into a position with the right side elevated fairly high during mobilization of the pancreas head, should not be hesitated.

Rosen et al. [16] described laparoscopic transduodenal resection of the major duodenal papilla, which was not laparoscopically assisted, in a case report. However, there is no consensus regarding laparoscopic resection of neoplastic lesions which originate in the intestinal mucosa by opening the intestine under aeroperitoneum, because the problems of peritoneal or port site seeding remain unresolved. Additionally, in LATDP, because the part of the duodenum including the major duodenal papilla is exposed through the minimum incision, it can be fixed firmly and spread easily after opening the side opposite to the major duodenal papilla. We could therefore obtain a better operation field than the complete laparoscopic method or conventional opening method. Thus, due to less invasion and cosmetic benefits, LATDP is suggested for resection of the major duodenal papilla in select patients.

Postoperatively, we managed these 2 patients similar to those undergoing TDP by the open method. In both patients, postoperative courses were uneventful, and food intake was started on POD 5 and 6, respectively. The postoperative hospitalization was relatively long (11 and 15 days), because the gastrostomy tube and the intestinal fistula tube, which had been placed to prepare for gastric stasis due to the attrition of peristalsis of the duodenum, had to be kept in place for 3 weeks without use. In the future, we will use the C-tube continuously, because a Ctube fixed to the cystic duct by elastic thread can be removed safely without bile leakage within a few days postoperatively [17]; however, our next patient will not receive a gastrostomy or intestinal fistula tube, thus facilitating an early discharge due to the change in our postoperative management.

\section{Conclusion}

LATDP is a feasible procedure for adenoma and cancer in adenoma of the major duodenal papilla that does not require prophylactic lymph node dissection; therefore, LATDP is a potential alternative to TDP, being less invasive than TDP and easier to perform than ESR, the least invasive procedure for these patients. 


\section{References}

$>1$ Howe JR, Klimstra DS, Moccia RD, Conlon KC, Brennan MF: Factors predictive of survival in ampullary carcinoma. Ann Surg 1998;228:87-94.

-2 Beger HG, Treitschke F, Gansauge F, Harada N, Hiki N, Mattfeldt T: Tumor of the ampulla of Vater: experience with local or radical resection in 171 consecutively treated patients. Arch Surg 1999;134:526-532.

- 3 Yoon YS, Kim SW, Park SJ, Lee HS, Jang JY, Choi MG, Kim WH, Lee KU, Park YH: Clinicopathologic analysis of early ampullary cancers with a focus on the feasibility of ampullectomy. Ann Surg 2005;242:92-100

$\checkmark 4$ Beger HG, Thorab FC, Liu Z, Harada N, Rau BM: Pathogenesis and treatment of neoplastic diseases of the papilla of Vater: KauschWhipple procedure with lymph node dissection in cancer of the papilla of Vater. J Hepatobiliary Pancreat Surg 2004;11:232238.

5 Kondo S, Takada T, Miyazaki M, et al: Guidelines for the management of biliary tract and ampullary carcinomas: surgical treatment. J Hepatobiliary Pancreat Surg 2008;15:41-54.
$6 \mathrm{Kim} J \mathrm{H}, \mathrm{Kim} J \mathrm{H}, \mathrm{Han} J \mathrm{H}$, Yoo BM, Kim MW, Kim WH: Is endoscopic papillectomy safe for ampullary adenomas with high-grade dysplasia? Ann Surg Oncol 2009;16:25472554.

7 Ryan DP, Schapiro RH, Warshaw AL: Villous tumors of the duodenum. Ann Surg 1986 203:301-306.

$>8$ Han J, Kim MH: Endoscopic papillectomy for adenomas of the major duodenal papilla (with video). Gastrointest Endosc 2006;63: 292-301.

9 Bohnacker S, Soehendra N, Maguchi H, Chung JB, Howell DA: Endoscopic resection of benign tumors of the papilla of Vater. Endoscopy 2006;38:521-525

10 Yamao T, Isomoto H, Kohno S, Mizuta Y, Yamakawa M, Nakao K, Irie J: Endoscopic snare papillectomy with biliary and pancreatic stent placement for tumors of the major duodenal papilla. Surg Endosc 2010;24:119_ 124.

11 Kim JH, Moon JH, Choi HJ, Lee HS, Kim HK, Cheon YK, Cho YD, Lee JS, Lee MS Shim CS: Endoscopic snare papillectomy by using a balloon catheter for an unexposed ampullary adenoma with intraductal extension (with videos). Gastrointest Endosc 2009;69:1404-1406.
12 Perti C, Pasquali C, Piccoli A, Sernagiotto C, Pedrazzoli S: Radical resection for ampullary carcinoma. Long term results. Br J Surg 1994;81:668-671.

13 Asbun HJ, Rossi RL, Munson JL: Local resection for ampullary tumors. Is there a place for it? Arch Surg 1993;128:515-520.

14 Rattner DW, Fernandez-del Castillo C, Brugge WB, Warshaw AL: Defining the criteria for local resection of ampullary neoplasms. Arch Surg 1996;131:366-371.

15 Beger HG, Staib L, Schoenberg MH: Ampullectomy for adenoma of the papilla and the ampulla of Vater. Langenbecks Arch Chir 1998;383:190-193.

16 Rosen1 M, Zuccaro G, Brody F: Laparoscopic resection of a periampullary villous adenoma. Surg Endosc 2003;17:1322-1325.

17 Kitano S, Bandoh T, Yoshida T, Shuto K: Laparoscopic C-tube drainage via cystic duct following common bile duct exploration. J Hepatobiliary Pancreat Surg 1995;2:146149. 